\title{
Toxicological Impact of Co-treatment with Rifampicin and Tenofovir on the Renal Function of Male Albino Rats
}

\author{
Adikwu Elias ${ }^{1, *}$, Igbans Rejoice Obele ${ }^{2}$, Brambaifa Nelson ${ }^{1}$ \\ ${ }^{1}$ Department of Pharmacology, Faculty of Basic Medical Sciences, University of Port Harcourt, Rivers State, Nigeria \\ ${ }^{2}$ Department of Community Health Sciences, College of Health Technology, Otuogidi, Bayelsa State, Nigeria
}

Copyright $\mathrm{O} 2016$ by authors, all rights reserved. Authors agree that this article remains permanently open access under the terms of the Creative Commons Attribution License 4.0 International License

\begin{abstract}
This experimental study comparatively evaluated the toxicological effects of treatment with tenofovir, rifampicin and tenofovir- rifampicin (TDF-RIF) combination on kidney function and histology of male albino rats. Male albino rats used in this study were divided into five (5) groups A-E of sixteen (16) animals each. Animals in group A, (placebo control) were treated orally with normal saline, group B (solvent control) were treated orally with $0.1 \%$ ethanol while groups $\mathrm{C}-\mathrm{E}$ were treated orally with $80 \mathrm{mg} / \mathrm{kg}$ of RIF, $32 \mathrm{mg} / \mathrm{kg}$ of TDF and a combination of TDF- RIF for 2-8 weeks respectively. Animals were sacrificed at the end of drug therapy, blood sample was collected, centrifuged and serum extracted for creatinine, urea and, uric acid evaluation. Kidney was harvested, weighed and examined for histopathological changes. Treatment with tenofovir-rifampicin combination had no significant $(p<0.05)$ effect on absolute kidney weight when compared with treatment using individual doses of these drugs. Insignificant $(p>0.05)$ time-dependent increases in serum creatinine, urea and uric acid levels were observed in animals treated with tenofovir-rifampicin combination when compared with treatment using individual doses of these drugs . Acute tubular necrosis, enlarged glomeruli and obliteration of the Bowman's capsule were observed in the kidneys of rats treated with tenofovir, rifampicin and a combination of tenofovir-rifampicin. This result shows that treatment with tenofovir-rifampicin combination in the management of human immunodeficiency virus /tuberculosis (HIV/TB) co-infection may not be associated with synergistic renal toxicity at the dose level used in this study.
\end{abstract}

Keywords Renal, Toxicity, Co-treatment, Tenofovir, Rifampicin, Rats

\section{Introduction}

Tenofovir is an acyclic nucleotide phosphonate diester analog of adenosine monophosphate. Similar to many Nucleoside Reverse Transcriptase Inhibitors (NRTIs) tenofovir inhibits HIV-1 reverse transcriptase by competing with the natural substrate deoxyadenosine 5 '-triphosphate, which is part of the nucleotide pools used by virus in generating cDNA $[1,2]$. It is an orally bioavailable prodrug that is widely prescribed due to its potency, convenient dosing, and a favorable safety and tolerability profile. It was approved by the US Food and Drug Administration (FDA) in 2001 and is recommended by World Health Organization (WHO) for use in adults and adolescents as preferred first-line nucleotide reverse transcriptase inhibitors in combination with other antiretroviral drugs for the management of Human Immunodeficiency Virus (HIV) infection [3]. It is available as a co-formulation with other antiretrovirals (ARVs) to make dual or triple once-daily fixed-dose combinations. When administered, tenofovir is eliminated by active tubular secretion and glomerular filtration with predominant accumulation in proximal renal tubular cells. $[4,5]$. The use of tenofovir is associated with proximal tubular dysfunction with or without decreased renal function. Renal impairments, characterized by acute renal failure, interstitial nephritis and Fanconi's syndrome, have been reported with the use of tenofovir in humans and animals $[6,7]$. Animal studies and case reports in humans showed that tenofovir might be associated with various degrees of kidney histopathological damage characterized by proximal tubular necrosis, chronic tubulointerstitial scarring, and ultrastructural mitochondrial abnormalities [8$10]$.

Rifampin is a large lipid soluble semisynthetic macrocyclic antibiotic produced from streptomyces mediterranei. It is a first-line drug mostly used in combination with isoniazid, ethambutol and pyrazinamide in the treatment of all forms of tuberculosis caused by organisms with known or presumed sensitivity to the drug. It has activity against organisms that are dividing rapidly (early bactericidal activity) and against semidormant bacterial populations, thus accounting for its sterilizing activity [11]. 
It acts by binding to $\beta$ subunit of bacterial DNA-dependent RNA polymerase in prokaryotic, but not in eukaryotic cells thereby inhibiting RNA synthesis [12]. Rifampicin is said to be safe, but it has been associated with adverse reactions such as nephrotoxicity sometimes resulting in acute renal failure [13]. Although deterioration of renal function, associated with acute tubulointerstitial nephritis and/or acute tubular necrosis, typically appears in patients receiving intermittent rifampicin therapy, some authors have also reported cases occurring during continuous rifampicin therapy $[14,15]$. Studies have shown that rifampicin is associated with histopathological changes characterized by glomerular distortion glomerulonephritis, interstitial nephritis and/or acute tubular necrosis $[16,17]$.

Despite the fact that rifampicin and tenofovir are individually associated with renal toxicity these drugs are usually co-administered in the management of human immunodeficiency virus/ tuberculosis co-infection $[18,19]$. The direct exposure of the kidney to co-administered rifampicin - tenofovir could be associated with overlapping renal toxicity that may alter the anatomical structure of the kidney thereby impairing its physiological functions. The kidney is an essential organ required by the body to perform several important functions including the maintenance of homeostasis, regulation of the extracellular environment, such as detoxification, and excretion of toxic metabolites and drugs [20]. Kidney is frequently subjected to high concentrations of potentially toxic drugs and their metabolites due to its involvement in drug metabolism [21]. Direct or indirect exposure and accumulation of drugs and metabolites in the kidney could lead to a variety of nephrotoxic effects [22]. This study was therefore designed to investigate the effects of co-treatment with tenofovirrifampicin on kidney function and histology of adult male albino rats.

\section{Materials and Methods}

Animals

Eighty (80) adult male albino rats of average weight 350 $\pm 5 \mathrm{~g}$ which were divided into five groups A-E of sixteen (16) animals each were used in this study. The animals were obtained from the animal house of the Department of Pharmacology and Toxicology, Madonna University, Elele, Rivers State. The animals were allowed to acclimatize for 14 days and had free access to food and water ad libitum.

\section{Drugs}

Rifampicin used in this study was manufactured by Mancare Pharmaceuticals, India while pure sample of tenofovir disoproxil fumaratewas purchased from Shijiazhuang Aopharm Import \& Export Trading Co., Ltd. Shijiazhuang, China. Both drugs were of analytical grade. The doses of rifampicin and tenofovir disoproxil fumarate used in this study are $80 \mathrm{mg} / \mathrm{kg}$ and $32 \mathrm{mg} / \mathrm{kg}$ respectively which are higher than the clinically recommended doses [23, 24]. Rifampicin was dissolved in $0.1 \%$ ethanol while tenofovir disoproxil fumarate powder was suspended in normal saline $[25,26]$

\section{Grouping of Animals and Drug Administration}

Animals were group into five groups A- E of 16 animals per group. Animals in each group were further sub divided into four groups of four animals each. Animals in group A (placebo control) were treated with normal saline, while animals in group B (solvent control) were treated with $0.1 \%$ ethanol orally. Animals in groups C-E were treated with 80 $\mathrm{mg} / \mathrm{kg}$ of RIF, $32 \mathrm{mg} / \mathrm{kg}$ of TDF and a combination of TDFRIF orally for 2-8 weeks respectively.

\section{Collection of Sample for Analysis}

At 2, 46 and 8 weeks, after overnight fast, $2 \mathrm{mls}$ of blood samples were collected from the rats under chloroform anesthesia by cardiac puncture into sterile sample container and allowed to clot. Thereafter, plasma was separated by centrifugation at $1200 \mathrm{rmp}$ for $15 \mathrm{~min}$ and used for analysis. The animals were then killed by over dose of chloroform anesthesia; kidneys were dissected out, cleaned off the extraneous tissue, weighed and evaluated for histopathological changes.

\section{Evaluation of Serum Renal Function Parameters}

Serum urea, uric acid and creatinine levels were determined as described by Kind \& King 1954 [27] Annino \& Giese 1979[28] Toro \& Ackermann 1975[29]

\section{Histopathological Analysis}

Kidney tissue was fixed in $10 \%$ buffered formalin for $24 \mathrm{~h}$ at room temperature; the slices were embedded in paraffin and then sectioned. Four micrometer-thick paraffin sections were stained with hematoxylin and eosin for light microscope examination. The photomicrographs of the relevant stained sections were taken with the aid of a light microscope.

\section{Statistical Analysis}

Data were expressed as mean values \pm SEM. Analysis of data was performed with one-way analysis of variance (ANOVA).Statistical significance was set at $p<0.05$.

\section{Results}

\section{Effects on absolute Kidney Weight and Serum Creatinine}

There wasn't any significant $(p>0.05)$ change in kidney weight of animals treated with TDF, RIF and a combination of TDF- RIF with respect to the control [Table 1]. In our study, we observed that treatment with TDF time-dependently increased serum creatinine level to $109.2 \pm 2.20,117.1 \pm 3.21,124.1 \pm 2.12$ and $146.2 \pm 0.13$ while treatment with RIF increased serum creatinine level 
time-dependently to $106.6 \pm 0.71,113.75 \pm 1.21,123.5 \pm 3.00$ and $144.7 \pm 2.14$. These increases were found to be significant $(p<0.05)$ only at week 8 when compared with the control. Treatment with a combination of TDF - RIF produced insignificant $(p>0.05)$ time- dependent increases in creatinine level when compared with treatment with individual doses of TDF and RIF, but increase was significant $(p<0.05)$ at week 8 when compared with the control [Table 2].

Table 1. Effects of treatment with tenofovir, rifampicin and tenofovir,-rifampicin combination on absolute kidney weight $(\mathrm{g})$ in rats

\begin{tabular}{ccccc}
\hline Dose & WK2 & WK4 & WK6 & WK8 \\
\hline $\begin{array}{c}\text { Control } \\
\text { TDF }\end{array}$ & $0.63 \pm 1.15$ & $0.66 \pm 2.15$ & $0.65 \pm 3.00$ & $0.62 \pm 1.13$ \\
$\begin{array}{c}80 \mathrm{mg} / \mathrm{kg} \\
\text { RIF }\end{array}$ & $0.67 \pm 3.22$ & $0.64 \pm 2.43$ & $0.66 \pm 2.43$ & $0.63 \pm 2.04$ \\
$32 \mathrm{mg} / \mathrm{kg}$ & $0.65 \pm 2.10$ & $0.64 \pm 2.72$ & $0.70 \pm 1.33$ & $0.63 \pm 2.51$ \\
$\mathrm{TDF} / \mathrm{RIF}$ & $0.70 \pm 2.31$ & $0.67 \pm 3.21$ & $0.71 \pm 1.20$ & $0.64 \pm 1.16$ \\
\hline
\end{tabular}

TDF: tenofovir, RIF: rifampicin. Results are expressed as mean \pm SEM.

Table 2. Effects of treatment with tenofovir, rifampicin and tenofovir,-rifampicin combination on serum creatinine $(\mu \mathrm{mol} / 1)$ in rats

\begin{tabular}{ccccc}
\hline Dose & WK2 & WK4 & WK6 & WK8 \\
\hline Control & $101.7 \pm 1.21$ & $102.2 \pm 2.10$ & $105.3 \pm 3.12$ & $103.1 \pm 0.15$ \\
TDF & $109.2 \pm 2.20$ & $117.1 \pm 3.21$ & $124.1 \pm 2.12$ & $146.2 \pm 0.13^{*}$ \\
$80 \mathrm{mg} / \mathrm{kg}$ & & & & \\
RIF & $106.6 \pm 0.71$ & $113.75 \pm 1.21$ & $123.5 \pm 3.00$ & $144.7 \pm 2.14^{*}$ \\
$32 \mathrm{mg} / \mathrm{kg}$ & & $119.25 \pm 1.25$ & $124.3 \pm 1.25$ & $149.3 \pm 1.22^{*}$ \\
TDF/RIF & $110.1 \pm 1.22$ & 110
\end{tabular}

TDF: tenofovir, RIF: rifampicin. Results are expressed as mean \pm SEM, the superscript $(*)$ means significant difference with respect to the control at $p<0.05$ (ANOVA).

\section{Effects on Serum Urea}

Treatment with TDF produced time-dependent increases in serum urea, but significant $(p>0.05)$ increase to $6.5 \pm 0.03$ was only observed at week 8 only with respect to the control. Also RIF treated animals showed time-dependent increases in serum urea with significant $(p>0.05)$ increase observed only at week 8 when compared with the control. Furthermore combined treatment with TDF-RIF time-dependently increased serum urea to $4.97 \pm 3.00,5.21 \pm 2.12,5.42 \pm 0.21$ and $6.70 \pm 1.12$ for $2-8$ weeks respectively. These increases were insignificant $(p>0.05)$ when compared with treatment using individual doses of TDF and RIF [Table 3].

Table 3. Effects of treatment with tenofovir, rifampicin and tenofovir,-rifampicin combination on serum urea $(\mathrm{mmol} / \mathrm{l})$ in rats

\begin{tabular}{ccccc}
\hline Dose & WK2 & WK4 & WK6 & WK8 \\
\hline Control & $4.32 \pm 2.20$ & $4.40 \pm 1.20$ & $4.61 \pm 0.14$ & $4.41 \pm 0.31$ \\
TDF & $4.71 \pm 2.21$ & $5.02 \pm 2.13$ & $5.31 \pm 2.11$ & $6.58 \pm 0.03^{*}$ \\
$80 \mathrm{mg} / \mathrm{kg}$ & & & & \\
RIF & $4.60 \pm 2.13$ & $4.72 \pm 1.23$ & $5.13 \pm 0.23$ & $6.37 \pm 2.11^{*}$ \\
$32 \mathrm{mg} / \mathrm{kg}$ & & $5.21 \pm 2.12$ & $5.42 \pm 0.21$ & $6.70 \pm 1.12^{*}$ \\
TDF/RIF & $4.97 \pm 3.00$ & 5
\end{tabular}

TDF: tenofovir, RIF: rifampicin. Results are expressed as mean \pm SEM, the superscript $(*)$ means significant difference with respect to the control at $p<0.05$ (ANOVA).

\section{Effects on Serum Uric Acid and Kidney Histology}

Treatment with TDF produced insignificant $(p>0.05)$ time-dependent increases in serum uric acid when compared with the control. Treatment with RIF also produced insignificant $(p>0.05)$ time-dependent increases in serum uric acid when compared with the control. In animals treated with a combination of TDF- RIF, time-dependent increases in serum uric acid levels were observed. These increases were insignificant $(p>0.05)$ when compared with treatment using individual doses of these drugs [Table 4]. Kidney of animals' exposure to TDF, RIF, and a combination of TDF- RIF showed histopathological changes characterized by tubular necrosis, enlarged glomeruli and obliteration of the Bowman's capsule [Fig 2-4].

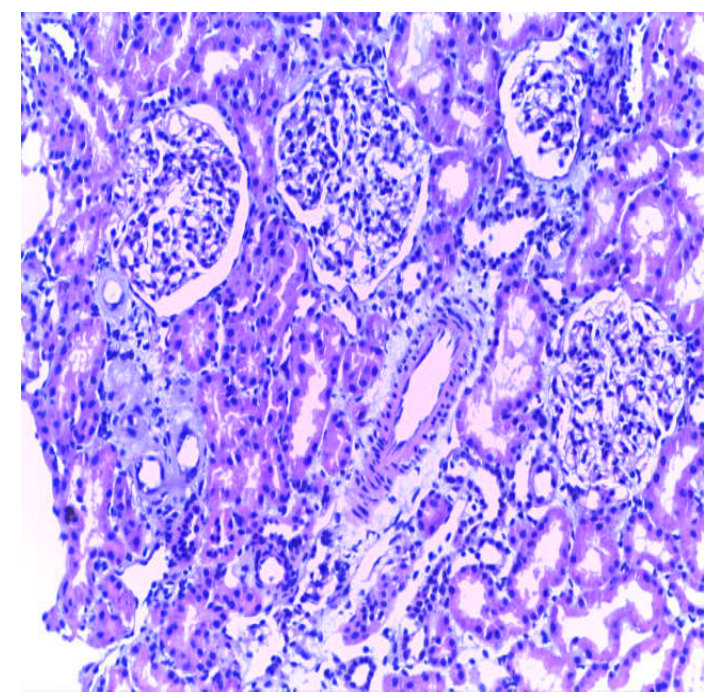

Figure 1. Photomicrograph of $\mathrm{H}$ and $\mathrm{E}$ stained section of the kidney of control rat treated with $0.1 \%$ ethanol for 8 weeks showing normal kidney histology. (x400)

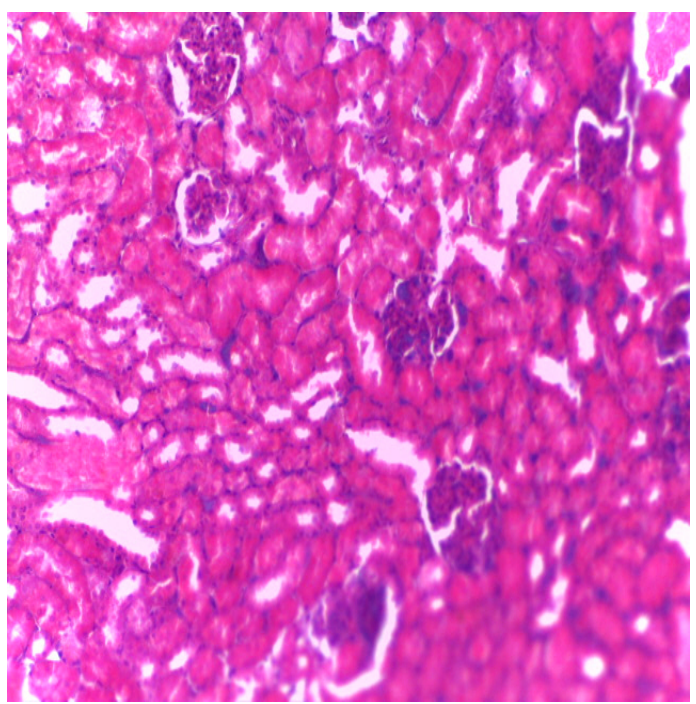

Figure 2. Photomicrograph of $\mathrm{H}$ and $\mathrm{E}$ stained section of the kidney of control rat treated with $80 \mathrm{mg} / \mathrm{kg}$ of rifampicin showing acute tubular necrosis. (x400) 


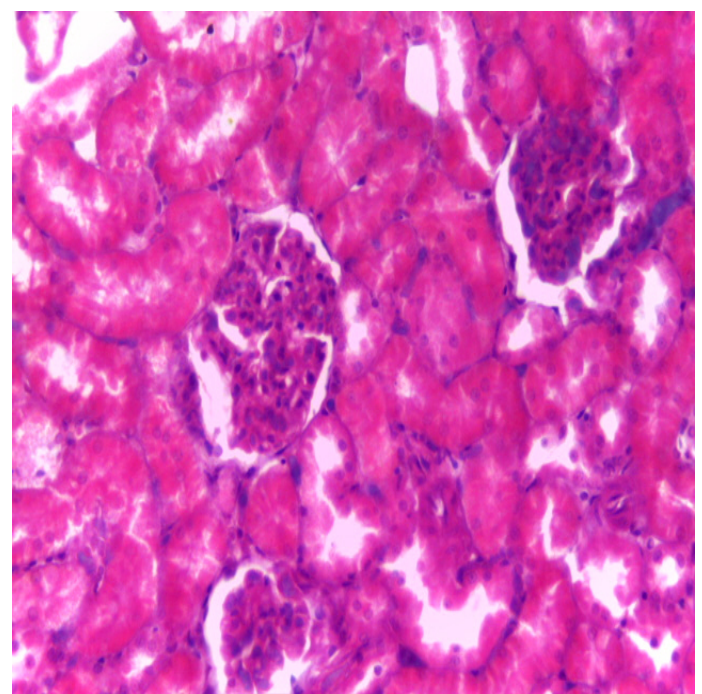

Figure 3. Photomicrograph of $\mathrm{H}$ and $\mathrm{E}$ stained section of the kidney of rat treated with $32 \mathrm{mg} / \mathrm{kg}$ of tenofovir for 8 weeks showing acute tubular necrosis and enlarged glomeruli and obliteration of the Bowman's capsule. $(\mathrm{x} 400)$

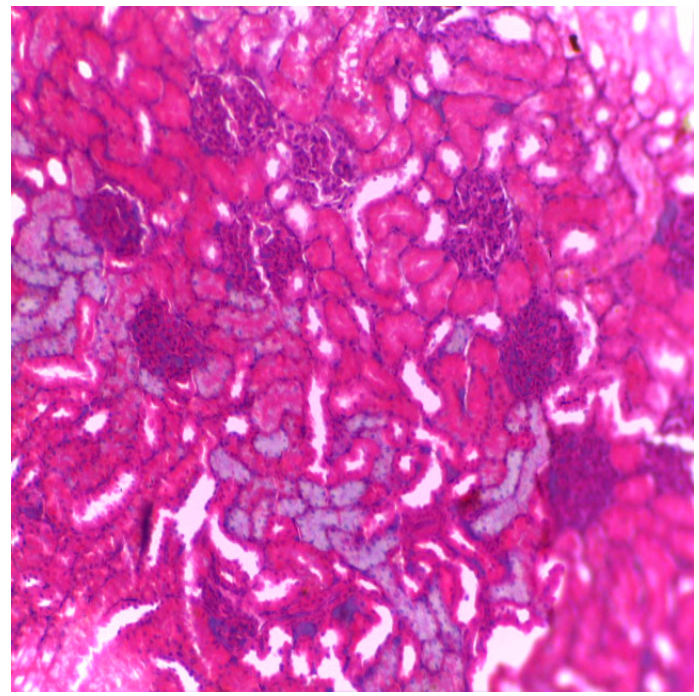

Figure 4. Photomicrograph of $\mathrm{H}$ and $\mathrm{E}$ stained section of the kidney of rat treated with combined doses of $80 \mathrm{mg} / \mathrm{kg}$ of rifampicin and $32 \mathrm{mg} / \mathrm{kg}$ of tenofovir for 8 weeks showing acute tubular necrosis and enlarged glomeruli obliteration of Bowman's capsule. $(x 400)$

Table 4. Effects of treatment with tenofovir, rifampicin and tenofovir,-rifampicin combination on serum uric acid (mg/dl) in rats

\begin{tabular}{ccccc}
\hline Dose & WK2 & WK4 & WK6 & WK8 \\
\hline Control & $1.51 \pm 2.00$ & $1.53 \pm 1.13$ & $1.50 \pm 3.12$ & $1.52 \pm 1.12$ \\
TDF & $1.57 \pm 2.30$ & $1.60 \pm 3.10$ & $1.65 \pm 1.15$ & $1.77 \pm 0.74$ \\
$80 \mathrm{mg} / \mathrm{kg}$ & & & & \\
$\mathrm{RIF}$ & $1.54 \pm 1.53$ & $1.57 \pm 0.64$ & $1.60 \pm 3.10$ & $1.67 \pm 1.12$ \\
$32 \mathrm{mg} / \mathrm{kg}$ & & & & \\
$\mathrm{TDF} / \mathrm{RIF}$ & $1.59 \pm 2.70$ & $1.65 \pm 3.12$ & $1.68 \pm 3.13$ & $1.79 \pm 2.14$
\end{tabular}

TDF: tenofovir, RIF: rifampicin. Results are expressed as mean $\pm \mathrm{SEM}$.

\section{Discussion}

Toxic effects on the kidney related to medications are both common and expected, given the kidney's roles in plasma filtration and maintenance of metabolic homeostasis. Renal dysfunction and injury secondary to medications can present as subtle injury and/or overt renal failure. Some drugs perturb renal perfusion and induce loss of filtration capacity while others directly injure vascular, tubular, glomerular and interstitial cells [30]. This study comparatively assessed time-dependent toxicological effects of treatment with tenofovir, rifampicin, and tenofovir-rifampicin combination on kidney function and histology of adult male albino rats which no study has been done. Evaluation of the effects of drugs on organ weight is an essential aspect of toxicological assessment [31]. In this study, treatment with a combination of tenofovir-rifampicin did not produce any significant $(p>0.05)$ change in absolute kidney weight when compared with treatment using individual doses of these drugs [32, 33]. Co-treatment with tenofovir-rifampicin produced time-dependent increases in creatinine, urea and uric acid, but increases were not significant $(p>0.05)$ when compared with treatment using individual doses of tenofovir and rifampicin. Observation in this study shows that co-therapy with tenofovir-rifampicin in HIV/TB co-infection may not be associated with synergistic renal toxicity.

In this study, we observed a time-dependent increase in serum creatinine level in tenofovir treated animals which is a sign of renal toxicity and is consistent with previous studies that were not time-correlated $[34,35]$. Noted increase in serum urea in tenofovir treated animals was time-dependent and is also a sign of renal toxicity. This observation is consistent with the work of Adaramoye and others who reported increase in serum urea in rats treated with $50 \mathrm{mg} / \mathrm{kg}$ of TDF for 4 weeks $[36,37]$. Our current study observed increase in serum uric acid in tenofovir treated animals which agree with the work of Abraham and others who reported increase in serum uric acid in rats treated with $600 \mathrm{mg} / \mathrm{kg}$ of TDF for 5 weeks [38]. Histopathological examination of the kidney of tenofovir treated animals revealed kidney damage characterized by acute tubular necrosis, enlarged glomeruli and obliteration of the Bowman's capsule. This finding is consistent with a study which shows that animals treated with $600 \mathrm{mg} / \mathrm{kg}$ of tenofovir for 35 days produced proximal tubular and glomerular damage [39]. Lebrecht and colleagues also exposed rats to tenofovir and reported proximal tubular dilatation and necrosis which is consistent with our observation [40]. Tenofovir induced kidney damage observed in our current study could be attributed to tenofovir induced oxidative stress. Reports have associated tenofovir with accumulation in renal tubules, lipid peroxidation, generation of oxidative radicals and the down regulation of kidney antioxidants [41].

Furthermore, we observed increases in serum creatinine and urea levels in rifampicin treated animals which is in agreement with previous reports [42-46]. The increase in 
serum uric acid level in rifampicin treated animals observed in this study agrees with a reported investigation by Shabana and colleagues who treated rats with $200 \mathrm{mg} / \mathrm{kg}$ of rifampicin for 30 days [47]. In this present study, histopathological examination of kidney of rifampicin treated animals' revealed tubular necrosis which is in resonance with reported observations by Tada and coresearchers who observed rifampicin induced mild nephrotic syndrome, showing glomerular abnormalities and slight interstitial changes [48]. Our findings are validated by the work of De Vriese et al [49] who reported that acute tubular necrosis is the predominant pattern in renal biopsies during acute renal failure attributed to intermittent rifampicin therapy. The mechanism by which rifampicin induced kidney damage has been attributed to immune complex deposition in the blood vessels or interstitium which may cause glomerular endotheliosis leading to tubular injury [50]. Interestingly, observed increases in serum urea, creatinine, and uric acid induced by these drugs could be correlated with histopathological changes observed in the kidney of treated animals.

\section{Conclusions}

Treatment with tenofovir-rifampicin combination produced time-dependent increases in creatinine, urea, and uric acid levels, but increases were not significant $(p>0.05)$ when compared with treating using individual doses of these drugs. Histopathological damage characterized by acute tubular necrosis, enlarged glomeruli and obliteration of the Bowman's capsule were observed with treatment with tenofovir-rifampicin combination. Treatment with tenofovir-rifampicin combination in the management of HIV/TB may not be associated with synergistic renal toxicity, but patients renal function status should be considered before co-administration of tenofovir-rifampicin.

\section{Acknowledgements}

We appreciate the technical assistance of Mr. Eze Iheukwumere of the animal house of the Faculty of Pharmacy, Madonna University, Elele. Our appreciation also goes to Mr. Charles Okeibunor of the Faculty of Pharmacy, Madonna University, Elele, Rivers State, Nigeria.

\section{REFERENCES}

[1] KA. Lyseng-Williamson, NA. Reynolds, GL. Plosker. Tenofovir disoproxil fumarate: a review of its use in the management of HIV infection. Drugs. Vol. 65, 413-432, 2005

[2] V. Vivet-Boudou, J. Didierjean,C. Isel , et al. Nucleoside and nucleotide inhibitors of HIV-1 replication. Cellular and Molecular Life Science. Vol. 63:163-186, 2006
[3] Technical update on treatment optimization Use of tenofovir in HIV-infected children and adolescents: a public health perspective June 2012

[4] PE. Sax , JE. Gallant, PE. Klotman Renal safety of tenofovir disoproxil fumarate. AIDS Reader Vol. 17, No. 90-92, 99-104, 2007

[5] B. Fernandez-Fernandez, A. Montoya-Ferrer, A. B. Sanz, M. D. Sanchez-Niño, Maria C. Izquierdo, Tenofovir nephrotoxicity: 2011 update. AIDS Research and Treatment, Vol.2011, Article ID. 354908, 2011

[6] Viread (2006) prescribing information. Gilead Sciences, Foster City, California

[7] E, Adikwu, O. Ijeoma, N. Edikpo, D. Oputiri, O. P. Geoffrey, Tenofovir Renal Toxicity: Evaluation of Cohorts and Clinical Studies - Part One, Pharmacology \& Pharmacy, Vol.4, 651-662, 2013

[8] M.A. Perazella Tenofovir-induced kidney disease: an acquired renal tubular mitochondriopathy Kidney International Vol. 78, 1060 - 1063, 2010

[9] L.C. Herlitz , S. Mohan, MB. Stokes et al. Tenofovir nephrotoxicity: acute tubular necrosis with distinctive clinical, pathological, and mitochondrial abnormalities . Kidney International. Vol. 7, No. 8: 1171 - 1177, 2010

[10] J. Kohler, S. Hosseini, A. Hoying-Brandt A e $t$ al.Tenofovir renal toxicity targets mitochondria of renal proximal tubules Laboratory Investigation, Vol. 89,513 - 519, 2009

[11] V. Somaraja Drugs used in the management of tuberculosis IV chemotherapy, 49, 557-566

[12] FB. Geo., C, C. Karen, J S. Butel, S A. Morse, A. M. Timothy. Melnick and Alderberg"s medical microbiology: McGrawhill, 2010

[13] A. Jover-Saenz, J. M. Porcel-Perez, AB, Madrona, S. Bielsa-Martin: Acute interstitial nephritis due to rifampicin. Enfermedades Infecciosasy Microbiology Clinica Vol 24:64, 2006

[14] S. Aminiafshar, M, Alimagham, F. Abbasi, SK. Fard-Khani: Acute interstitial nephritis associated with rifampicin therapy. Saudi Journal of Kidney Diseases and Transplantation Vol. 20:1079-1080, 2009

[15] H. K. Min, EO. Kim, S J. Lee, YK. Chang, K S, Suh, et al., Hwang1Rifampin-associated tubulointersititial nephritis and Fanconi syndrome presenting as hypokalemic paralysis,. BMC Nephrology, Vol. 14:13, 2-5, 2013

[16] SB. Salih, M. Kharal, M. Qahtani, L. Dahneem, S. Nohair,.Acute interstitial nephritis induced by intermittent use of rifampicin in patient with brucellosis. Saudi Journal of. Kidney Diseases. And Transplantation. Vol. 19, No. 3, 450452, 2008

[17] S.D. Warner. Nephrotic syndrome in rhesus monkeys. Abstracts of cases presented at the 25th Annual meeting American college of veterinary pathologists. Vetinary Pathology. Vol.12, 61-73, 1975

[18] Managing Drug Interactions in the Treatment of HIV-Related Tuberculosis National Center for HIV/AIDS, Viral Hepatitis, STD, and TB Prevention Division of Tuberculosis Elimination 
[19] AL. Pozniak, KM. Coyne, RF. Miller , MC. Lipman, Freedman, ARF Ormerod, LP Johnson, MA SCollins S and Lucas, SB HIV British HIV Association guidelines for the treatment of TB/HIV coinfection 2011 Medicine Vol. 12, $517-524,2011$

[20] M A, Ferguson SV, Vaidya, JV Bonventre Biomarkers of nephrotoxic acute kidney injury. Toxicology. Vol. 245:182193, 2008

[21] JK. Aronson, Drugs and renal insufficient Medicine, Vol. 1 103-109, 2003

[22] I. E, Asangansi, AO. Oshin, OA. Akinloye. Drug nephrotoxicity. Ifemed J Med. 2005; Available at http://www.imeasangansi. org/pdf/drug\%20nephrotoxicity.pdf.

[23] Centers for Disease Control and Prevention. Treatment of Tuberculosis, American Thoracic Society, CDC, and Infectious Diseases Society of America. Morbidity and Mortality Monthly Reports, Vol.52 No. 11. 2003

[24] Viread [tenofovir disoproxil fumarate] package insert. Foster City, CA: Gilead Sciences, 2001 revissed 2013

[25] D. Theja T, Vishnuvardhan Rao P. Jamuna and AN. Sabitha Approach to Increase the solubility of rifampicin by solid dispersion technique, International Journal of Pharmaceutical Sciences and Research Vol. 3 No. 6, $1800-1805,2013$

[26] SV. Sutar S,S, Patil, S A, Pishvikar and HN, More spectrophotometric method for degradation study of tenofovir disopoxil fumarates, International Journal of Pharmaceutical Sciences and Research Vol. 3, No.11: 4363-4366, 2012

[27] P RN Kind, and E. J. King, Estimation of plasma phosphatase by determination of hydrolysed phenol with aminoantipyrine. Journal of Clinical. Pathology. Vol. 7, 322-326, 1954

[28] J. S. Annino, and R. W. Giese, Clinical Chemistry, 4th ed. Little Brown, Boston, pp 170-177, 1979

[29] G. Toro, and P. G. Ackermann, P.G. Practical clinical chemistry. Little Brown, Boston, pp 148-156, 1975

[30] D.Choudhury and Z. Ahmed, Drug-associated renal dysfunction and injury, Nature Clinical Practice Nephrology 2006 Vol 2 No 2, 80-91, 2006

[31] B. Michael , B. Yano, R. S. Sellers, R. Perry, D. Morton, N, Roome et al.,. Evaluation of Organ Weights for Rodent and Non-Rodent Toxicity Studies: A Review of Regulatory Guidelines and a Survey of Current Practices. Toxicologic. Pathology. Vol. 35 No. 5, 742-750, 2007

[32] WG, Miller, E. Myers., A, A, Ashwood., E. Killeen., L.M. Wang, et al. Creatinine Measurement State of the Art in Accuracy and Interlaboratory Harmonization. Archives of Pathology \& Laboratory Medicine, Vol. 3, 297-304, 2005

[33] T. Rudra, d. b.Webb , AG. Evans. Acute tubular necrosis following co-trimoxazole therapy. Nephron Vol, 53: 85-6, 1989

[34] T. Antoniou, J. M. Raboud, S. Chirhin, D. Yoong, V. Govan, Eet al Incidence of and risk factors for tenofovir-induced nephrotoxicity: a retrospective cohort study HIV Medicine
Vol. 6, 284-290, 2005

[35] K. K. Patel, A. Patel, R. Ranjan,, AR. Patel, Patel, Jtenofovir associated renal dysfunction in clinical practice: observational cohort from western India Ind. Sex Tran. Dis and AIDs, Vol. 31 No. 1, 30-34, 2010

[36] OA. Adaramoye , OM. Adewumi, OA, Adesanoye , OO. Faokule, EO. Farombi . Effect of tenofovir, an antiretroviral drug, on hepatic and renal functional indices of Wistar rats: protective role of vitamin E. Journal of Basic and Clinical Physiology and Pharmacology Vol 23, No. 2, 69-75, 2012

[37] BT. Schleenvoigt, A. Stallmach, M, W. Pletz tenofovir induced acute kidney injury in a patient with unilateral renal agenesis despite initially non-impaired renal function, European Journal of Medical Research Vol 16: 564, 2011

[38] P. Abraham, H, Ramamoorthy and B. Isaac, B Depletion of the cellular antioxidant system contributes to tenofovir disoproxil fumarate - induced mitochondrial damage and increased oxido-nitrosative stress in the kidney, Journal of Biomedical Science, Vol. 20:61, 3-15, 2013

[39] H. Ramamoorthy, P. Abraham and B. Isaac Preclinical efficacy of melatonin in the amelioration of tenofovir nephrotoxicity by the attenuation of oxidative stress, nitrosative stress and inflammation in rats, Journal of Basic Clinical Physiology and Pharmacology Vol. 25, No. 4, 387399, 2014

[40] D. Lebrecht, A. Venhoff, J. Kirschner e $t$ al. Mitochondrial tubulopathy in tenofovir disoproxil fumarate-treated rats. $\mathrm{J}$ Acquired Immune Deficiency Syndrome, Vol5 1: 1 58- 1 63, 2009,

[41] H. Ramamoorthy, P. Abraham, B. Isaac Oxidative stress, decreased activities of anti-oxidant enzymes, and neutrophil infiltration contribute to Tenofovir disoproxil fumarate induced renal damage in rats, International Research of Pharmacy and Pharmacology Vol. 1 No. 10, 259-270, 2011

[42] VV. Rekha, T. Santha, MS. Jawahar, Rifampicin-induced Renal Toxicity During Retreatment of Patients with Pulmonary Tuberculosis Journal of Asociation of Physicians of India Vol. 53, 811-813, 2005

[43] Opromolla, D.V.A. Adverse Reactions to Rifempicin with special reference to acute renal failure. Hansen International Vol, 17, No. 1/2, 5-7, 1992

[44] S. Rosati, C. Cherubini, F. Iacomi, K. Giannakakis Acute rifampicin-associated interstitial tubulopathy in a patient with pulmonary tuberculosis, Journal of Medical Case Reports Vol, 7:106, 2013

[45] DE. Peters, and AO. Chike Effect of rifampicin on the kidney of albino rats, Journal of Applied Sceince and Environmental Management. Vol. 17, No. 1, 125-131, 2013

[46] TC. Havey, C. Cserti-Gazdewich, M. Sholzberg, JS. Keystone, and W.L. Gold, Case Report: Recurrent Disseminated Intravascular Coagulation Caused by Intermittent Dosing of Rifampin American. Journal of. Tropical. Medicine. Hygiene. Vol 86 No. 2, 264-267, 2012

[47] MB. Shabana, M. IbrahimH, EM. Khadre, MG. Elemam, Influence of rifampicin and tetracycline dministration on some biochemical and histological parameters in albino rats The Journal of Basic \& Applied Zoology, Vol. 65, 299-308, 2012 
[48] T. Tada, A. Ohara, Y. Nagai, M. Otani, YC. Ger, \& SA. Kawamura, case report of nephrotic syndrome associated with rifampicin therapy. Japan Journal of Nephrology. Vol. 37: 145-150, 1994

[49] AS. De Vriese, DL. Robbrecht, R. C, Vanholder , DP, Vogelaers, NH, Lameir. Rifampicin associated acute renal failure: pathophysiologic, immunologic and clinical features. American Journal of Kidney Disease, Vol. 31:108-15, 1998

[50] T. Muthukumar , M. Jayakumar, E. Fernando, MA, Muthusethupathi . Acute Renal Failure Due to Rifampicin. A study of 25 patients. American Journal of Kidney Disease Vol. 40, 690-6, 2002 